\title{
Study of corrosion characteristics of motor oils used in gas-diesel engines of BelAZ mining dump trucks
}

\author{
Georgiy Dubov ${ }^{1 *}$, Alexander Bogomolov ${ }^{1,2}$, Elena Grigorieva $^{1}$, Pavel Strelnikov $^{1}$, and \\ Sergey Nokhrin ${ }^{3}$ \\ ${ }^{1}$ T.F. Gorbachev Kuzbass State Technical University, Department of Mechanical Engineering \\ Technology, 28 Vesennyaya st., Kemerovo, the Russian Federation \\ ${ }^{2}$ Kutateladze Institute of Thermophysics SB RAS, Academician Lavrentyev Prospect, 1, \\ Novosibirsk, the Russian Federation \\ ${ }^{3}$ «TekhnoEco» LLC, 11 Azovskaya St., Prokopyevsk, the Russian Federation
}

\begin{abstract}
Comparative studies of the corrosion characteristics of motor oils used in internal combustion engines of BelAZ 75131 mining dump trucks using liquefied natural gas - methane - as a motor fuel are presented. It is noted that an increase in the lead concentration in waste oil of internal combustion engines of mining dump trucks can be influenced by the used motor oil when it is interacting with the crank mechanism bearings liners, which have lead in their composition. The research technique is presented. The data on the $\mathrm{pH}$ values of the studied neat motor oils and their oil-in-water emulsions are given. It is noted that the effect of moisture and atmospheric oxygen on various types of motor oils of the same manufacturer's brand affects the formation of either water-soluble organic acids that contribute to the corrosion attack on lead or its alloys, or the formation of water-soluble alkaline organic compounds that have a neutral effect on lead and its alloys. This fact suggests that motor oils used in internal combustion engines of mining dump trucks have various corrosion characteristics that eventually affect the content of harmful impurities in waste oils.
\end{abstract}

\section{Introduction}

Open pit mining has become a leader in the mining industry due to its high productivity, low cost and safety. And it is this method that will be leading in the mining industry in the next decade. [1]. Despite the advantages of open-pit mining, there are a number of disadvantages, one of which is a high downtime rate of mining dump trucks due to the failure of their units and assemblies. A decrease in the reliability of units and assemblies of mining dump trucks occurs not only due to wear of friction surfaces during operation, but also due to the physical and chemical change in properties of oils, which in the process of operation accumulate metal impurities of products of wear and chemical interaction of the organic matrix of oils with materials of friction surfaces [2-5].

In order to timely prevent the failure of mining equipment assemblies at mining enterprises, waste oil is analyzed according to various criteria and methods. For example, emis-

*Corresponding author: nikokem@mail.ru 
sion spectral analysis of oil is carries out at the open-pit mines of OJSC "UK Kuzbassrazrezugol" using the MFS-7 multichannel photometric system. The system, using spectral analysis of mechanical impurities in oil, determines the concentration of metal particles in it: products of wear of parts (the content of alkali metals, $\mathrm{Ca}$ and $\mathrm{Ba}$ - the base of detergentdispersant and other additives to oils, silicon - the base of abrasive oil contaminants, which are the most dangerous [6].

Heavy-duty mining dump trucks with diesel internal combustion engines are most widely used for rock mass hauling in mining companies in Russia [7-13]. The fleets of open pit mining companies are mainly equipped with BelAZ-75131 mining dump trucks and their modifications. This is obviously due to the efficiency of using this model of mining dump trucks, which has a carrying capacity of 130 tons, at open-pit mines, taking into account mining, geological, economic and operational indicators.

Currently, taking into account the increasingly restrictive environmental regulations for open pit mining, as well as the need to increase its economic efficiency, projects are being implemented to create new open pit equipment and modernize the existing one [14]. One of such projects is the project implemented in Kuzbass to convert BelAZ 75131 heavy-duty mining dump trucks to dual-fuel gas-diesel operation. Today, about 60 BelAZ 75131 mining dump trucks with CUMMINS KTA 50 diesel engines are equipped with on-board cryogenic fuel systems and are successfully operated at the Kuzbass open-pits [15-20].

The analysis of the samples of waste oil from the internal combustion engines of the modernized gas-diesel BelAZ 75131 mining dump trucks has shown that the lead content of some of them increased to $30 \mathrm{~g} / \mathrm{t}$ and more. It is obviously negatively affected the internal combustion engine of mining dump trucks. According to the standards, engine oil is rejected, for example, by the KAMSS service center, if the lead content in waste internal combustion engine oil exceeds $10 \mathrm{~g} / \mathrm{t}$.

It should be noted that when the engines were operated with VALVOLINE PREMIUM BLUE 9200 15W40 ICE motor oil, there was a significant increase in the lead content, but when using VALVOLINE PREMIUM BLUE 7800 15W40 oil, also recommended by the CUMMINS manufacturer for use in engines, the little if any lead content in them was observed.

It should also be noted that the results of studies of liquefied natural gas (LNG), used in CUMMINS KTA-50 engines to partly replace diesel fuel, showed that the lead content in LNG was not determined due to its absence.

In the course of the analysis, it was suggested that the reason for an increase in the lead content when using VALVOLINE PREMIUM BLUE 9200 15W40 ICE oil may be its oxidizing properties caused by reactive additives to oil, including surfactants. The interaction of reactive additives with babbitt of the surface layer of the crank mechanism bearing liners entailed the lead component dissolution and its transition into the liquid phase of motor oil.

The crank mechanism bearing liners usually have a small layer of babbitt used in plain bearings. Lead and tin babbits according to GOST 1320-74 and ISO 4383, as well as calcium babbits according to GOST 1209-90, are used. Lead is the main element in calcium and lead babbits. To identify the reasons for an increase in the mass fraction of lead in waste VALVOLINE PREMIUM BLUE 9200 15W40 ICE oil and to exclude all other factors, the oil pan was opened, the piston and the connecting rod group and the crank mechanism were examined. No malfunctions of the babbit bearing liners were identified

ISO 4383 specifies requirements for multilayer materials for thin-walled plain bearings. The multilayer material of a bearing liner consists of a steel backing, a tin and lead overlay (cast, sintered, rolled). Electrolytic deposition top coating is possible. The chemical composition of steel for bearing liners is established by agreement between the manufacturer and the consumer. Low carbon steels are commonly used. The chemical composition of bearing 
alloys must correspond to the composition given in GOST 1320-74, in which tin and lead in various concentrations are mandatory elements.

A coating is applied to an overlay. The thickness of a coating or any additional layer between an overlay and a coating is set by agreement between the manufacturer and the consumer. In accordance with GOST 1320-74, lead is the main content in an overlay.

Many studies suggest that lubricating oils should not be corrosive to the materials of engine parts. On the other hand, the problem of corrosion of antifriction alloys used in plain bearings of internal combustion engines arises due to the widespread replacement of tin babbit with other alloys that differ from it in higher fatigue resistance and better mechanical properties, but have significantly lower anti-corrosion resistance. The latter is especially true for alloys such as copper-lead, lead babbitt and cadmium-based alloys. The lead component of alloys is the least resistant to corrosive products contained in oils. Therefore, the corrosion characteristics of oils are evaluated in terms of lead. The corrosion characteristics of oils depend on the presence of corrosive components (naphthenic acids) in them and on the tendency of oils to form corrosive agents as a result of oxidation (carboxylic and hydroxycarboxylic acids), which is determined by the hydrocarbon-type content of oil.

Considering the above, the question of the need to conduct research in the field of determining the corrosion characteristics of oils used in internal combustion engines of gasdiesel BelAZ 75131 mining dump trucks has arisen.

The purpose of the presented work is comparative studies of the distinctive features of corrosion characteristics of VALVOLINE PREMIUM BLUE $920015 \mathrm{~W} 40$ and VALVOLINE PREMIUM BLUE 7800 15W40 oils.

\section{Materials and Methods}

Corrodibility is an important performance characteristic of lubricating oils. This requirement for the motor oil quality is imposed due to the widespread use of easily corrodible non-ferrous metal alloys in engine building.

According to GOST 20502-75, the essence of methods for determining the corrosion characteristics of oils is to determine the change in the mass of metal plates subjected to periodic exposure to the test product and air heated to a temperature of $140^{\circ} \mathrm{C}$ (or to the temperature specified in the technical standard documentation).

The standard specifies two test methods:

1 - to determine the corrodibility of motor oils and additives to them with the DKNAMI instrument;

2 - to determine the corrodibility of oils and liquids intended for use in aviation and special equipment with an AP-1 apparatus (Pinkevich apparatus) on metal plates made of various materials.

The plate weight loss up to $1 \mathrm{~g} / \mathrm{m}^{2}$ inclusive when testing without adding a catalyst and up to $5 \mathrm{~g} / \mathrm{m}^{2}$ over a catalyst (copper naphthenate) is taken as the absence of corrosion.

GOST 6307-75 applies to liquid petroleum products, additives, greases, paraffins, ceresins, wax compositions and establishes a method for determining the presence of watersoluble acids and alkalis in them. The essence of the method is to extract water-soluble acids and alkalis from oil products with water or an aqueous solution of alcohol and determine the $\mathrm{pH}$ value of the aqueous extract with a $\mathrm{pH}$-meter or the reaction of the medium using indicators. In GOST 6307-75 it is noted that if an emulsion is formed when a petroleum product is mixed with water, then water-soluble acids and alkalis are extracted by treating the petroleum product with an alcohol solution $(1: 1)$ heated to $50-60^{\circ} \mathrm{C}$ (instead of distilled water).

The current oil standards require the absence of water-soluble acids and alkalis in oils and the limitation of the content of organic acids insoluble in water. The absence of water- 
soluble acids and alkalis in oils is checked qualitatively by extracting the aqueous extract with preheating to $70-80^{\circ} \mathrm{C}$ (according to GOST 6307-75). The presence of water-insoluble organic acids is determined quantitatively by extracting them from oil with boiling ethyl alcohol and subsequent titration with an alcoholic solution of $\mathrm{KOH}$, necessary to neutralize $1 \mathrm{~g}$ of oil (GOST 5985-79). Corrosion of metals under the influence of organic acids in oils depends on the amount and the properties of these acids, as well as the external conditions. The corrosiveness of organic acids is greatly increased by even a small amount of moisture in oils. Organic acids found in lubricating oils act on some non-ferrous metals and their alloys much more intensely than on ferrous ones.

In the presented work, the method for determining the corrodibility of the studied VALVOLINE PREMIUM BLUE 9200 15W40 and VALVOLINE PREMIUM BLUE 7800 $15 \mathrm{~W} 40$ oils according to GOST $6307-75$ was used by mixing motor oil with distilled water in a 1:1 ratio, but without extracting of water-soluble acids and alkalis with an alcohol solution.

\section{Results and Discussion}

According to GOST 6307-75, if an emulsion is formed when mixing oil with water, then water-soluble organic acids or alkalis are present in oil. Assuming that the source of lead accumulation in motor oil is babbitt of the upper layer of the bearing liners cooled by the VALVOLINE PREMIUM BLUE 9200 15W40 motor oil, which can presumably react to the babbitt composition, a study of the hydrogen parameters of samples of these oils was carried out. Studies were carried out both for neat oils and oils diluted with distilled water having a $\mathrm{pH}$ of 7.0 by mixing and stirring them to obtain an emulsion in a ratio of $50 / 50 \%$, vol. The studied VALVOLINE PREMIUM BLUE $920015 \mathrm{~W} 40$ and VALVOLINE PREMIUM BLUE $780015 \mathrm{~W} 40$ neat oils and their oil-in-water suspensions with the corresponding indexes 7800 and 9200 are shown in Fig. 1, 2.

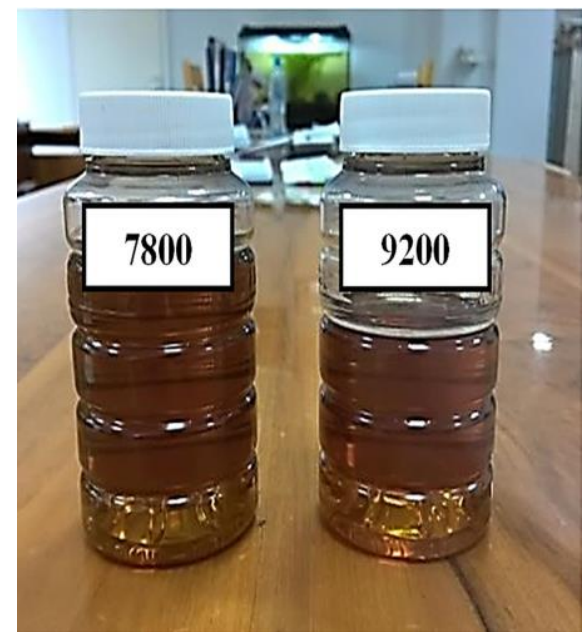

Fig. 1. The studied VALVOLINE PREMIUM BLUE $780015 \mathrm{~W} 40$ and VALVOLINE PREMIUM BLUE 9200 15W40 neat oils
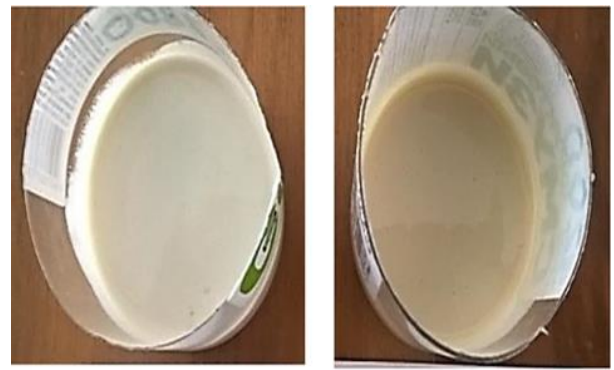

7800

\section{0}

Visual observations showed that the studied neat oils VALVOLINE PREMIUM BLUE 9200 15W40 (hereinafter 9200) and VALVOLINE PREMIUM BLUE 7800 15W40 (hereinafter 7800) have little differences in color (Fig. 1). However, oil-in-water emulsions of 
the studied oils have visible differences. So the VALVOLINE PREMIUM BLUE 7800 15 W40 oil-in-water emulsion had a beige color, and the VALVOLINE PREMIUM BLUE 9200 15W40 oil-in-water emulsions had an obvious darker shade - brown (Fig. 2).

Table 1 and Fig. 3 show the pH values of both the original neat oils and their oil-inwater emulsions (suspensions) and exposed to interaction with air for a long time (8 months). First of all, measurements were made on oil samples taken from the containers of the Cummins manufacturer into plastic cans with a hermetic seal (Fig. 1). When sampling on July 14, 2020, the $\mathrm{pH}$ was measured both for oils of the two studied brands and their oilin-water emulsions in order to exclude the prolonged effect of air on the oxidative and dissociation processes of oils and their emulsions. After the measurements, the "air cushion" over the initial oils in closed cans and oil-in-water emulsions remained above their surface. Further, the samples of oils and their emulsions were stored until 03/09/2021 in a stationary state and then repeated measurements of the $\mathrm{pH}$ were made.

Table 1. The $\mathrm{pH}$ values of the studied neat oils and their oil-in-water emulsions measured with a Testo $206 \mathrm{pH}$-meter at a temperature of $22-27^{\circ} \mathrm{C}$.

\begin{tabular}{|c|c|c|c|c|}
\hline \multirow{3}{*}{ State } & \multicolumn{4}{|c|}{ Test oils } \\
\cline { 2 - 5 } & \multicolumn{3}{|c|}{$\begin{array}{c}\text { VALVOLINE PREMIUM } \\
\text { BLUE 9200 15W40 }\end{array}$} & \multicolumn{2}{c|}{$\begin{array}{c}\text { VALVOLINE PREMIUM } \\
\text { BLUE 7800 15W40 }\end{array}$} \\
\cline { 2 - 5 } & $\mathbf{2 0 2 0}$ & $\mathbf{2 0 2 1}$ & $\mathbf{2 0 2 0}$ & $\mathbf{2 0 2 1}$ \\
\hline Neat oil & 6.7 & 6.39 & 7.0 & 6.67 \\
\hline Oil-in-water emulsion & 6.4 & 7.31 & 7.4 & 7.28 \\
\hline
\end{tabular}

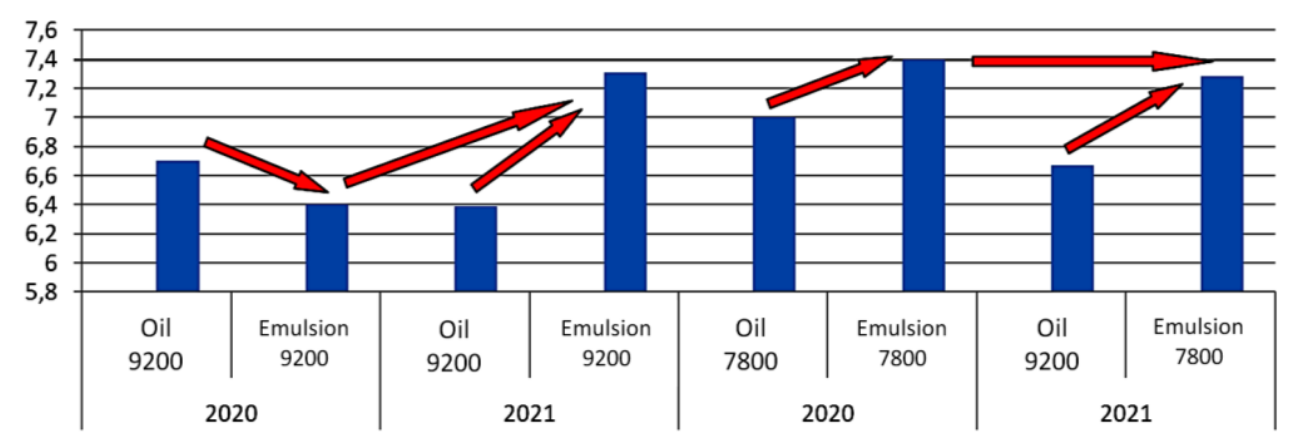

Fig. 3. The $\mathrm{pH}$ values of the studied neat oils and their oil-in-water emulsions

As shown by the results of the studies and as can be observed from the data presented in Table. 1 and Fig. 3, the $\mathrm{pH}$ value of the original VALVOLINE PREMIUM BLUE 7800 $15 \mathrm{~W} 40$ neat oil, measured in 2020 , is 7.0 and refers to a neutral medium $(\mathrm{pH}=7.0)$. The $\mathrm{pH}$ value of VALVOLINE PREMIUM BLUE $920015 \mathrm{~W} 40$ oil is 6.7, which indicates the acidic environment of this oil (the content of hydrogen ions $\left[\mathrm{H}^{+}\right]$is greater than that of hydroxide ions $\left.\left[\mathrm{OH}^{-}\right]\right)$. The $\mathrm{pH}$ value of VALVOLINE PREMIUM BLUE $780015 \mathrm{~W} 40$ oil-inwater emulsion increases from 7.0 to 7.4, i.e. interaction with an aqueous medium when creating an emulsion leads to an increase in the basic capacity of the medium (an increase in the concentration of hydroxide ions $\left[\mathrm{OH}^{-}\right]$in comparison with the content of hydrogen ions $\left[\mathrm{H}^{+}\right]$). The $\mathrm{pH}$ value of VALVOLINE PREMIUM BLUE $920015 \mathrm{~W} 40$ oil decreases from 6.7 to 6.4 , i.e. there is an interaction of the aqueous medium with oil, leading to an increase in the acidity of the medium.

It is obvious that, when the samples of the studied oils and emulsions are stored for eight months without insulation with contact with air, oxidative processes will occur, both 
in neat oils and in oil-in-water emulsions. In this regard, after this period, measurements were made of the $\mathrm{pH}$ of neat oils, exposed to a limited volume of "air cushion" of the environment, and their oil-in-water emulsions interacting with the external environment.

Fig. 3 shows that the $\mathrm{pH}$ value of neat 9200 oil after eight months of being above the oxidizing "air cushion" in an insulated vessel decreased from 6.7 to 6.39 , i.e. the acidity of oil has increased. Probably, the formation of carboxyl groups occurred. But the $\mathrm{pH}$ value of the emulsion, the surface of which was in contact with the air during this time, increased in from 6.4 to 7.31. Probably, water dissociation catalyzed by oil hydrocarbons occurred to form $\mathrm{OH}^{-}$anions and hydrogen cations, which were added to unsaturated open-chain hydrocarbons (alkenes, dienes, etc.), and the concentration of hydroxide ions $\left[\mathrm{OH}^{-}\right]$increased.

Regarding the behavior of 7800 oil when exposed to the environment, it can be noted that its initial state indicates a neutral product environment $(\mathrm{pH}=7.0)$. A period of eight months of environmental exposure influenced its $\mathrm{pH}$ value. It decreased from the initial value to 6.67 with a corresponding transition from neutral to slightly acidic. Probably, as with 9200 oil, the formation of carboxyl groups took place, which indicates the formation of hydrocarbon organic acids with the release of $\mathrm{H}^{+}$ions, which were replaced by atmospheric oxygen. The emulsion water-oil medium for a period of eight months, within the measurement error, had nearly the same concentration of hydroxide ions $\left[\mathrm{OH}^{-}\right]$(the $\mathrm{pH}$ value decreased from 7.4 to 7.28). The slowed down process of lowering the basic capacity of the emulsion, even in an insignificant concentration numerical value, is probably due to the unequal formation of carboxyl groups and the release of hydrogen ions $\left[\mathrm{H}^{+}\right]$.

It is known that lead is highly corrodible in various corrosive environments. In alkaline inorganic media, it is subject to intense corrosion, and in inorganic acids it is quite resistant. On the other hand, in environments with organic water-soluble alkalis, lead and its alloys are quite resistant, and in environments with organic water-soluble acids, they are easily corroded.

The data presented in Table 1 and Fig. 3 show that the neat oils used have a neutral medium $\mathrm{pH}=7.0$ (7800 oil) and an acidic medium $\mathrm{pH}=6.7$ (9200 oil). Information from available sources [11, GOST 2917-76] indicates that oils are susceptible to oxidation by exposure to atmospheric oxygen and moisture. In this case, water-soluble organic acids (naphthenic, carboxylic and other organic acids) can be formed, which are highly corrosive, primarily to lead contained in babbit.

The results shown in Table 1 and Fig. 3 also show that the effect of moisture on VALVOLINE PREMIUM BLUE $920015 \mathrm{~W} 40$ oil significantly affected the formation of watersoluble organic acids (the pH decreased from 6.7 to 6.4), and the effect of moisture on VALVOLINE PREMIUM BLUE 7800 15W40 oil influenced the formation of alkaline water-soluble organic compounds (there was an increase in $\mathrm{pH}$ from 7.0 to 7.4).

\section{Conclusion}

1. The studies conducted have shown that oils of the same brand, but different in type and used in CUMMINS KTA 50 diesel internal combustion engines of BelAZ 75131 mining dump trucks, have different corrosion characteristics.

2. The qualitative assessment of the studied oil samples indicates that the formation of water-soluble organic acids in VALVOLINE PRE-MIUM BLUE 9200 15W40 oil under the action of moisture and air oxygen contributes to an increase in the corrosive effect on lead or its alloys.

3. The action of moisture or air oxygen on the studied VALVOLINE PREMIUM BLUE $780015 \mathrm{~W} 40$ oil leads to the formation of water-soluble organic alkalis, which have a neutral effect on lead and its alloys. 
4. According to the criterion of corrosive effects and, as a consequence, a decrease in the concentration of lead in waste oil, VALVOLINE PREMIUM BLUE 7800 15W40 oil can be considered the most optimal for use in CUMMINS KTA 50 diesel internal combustion engines of BelAZ 75131 mining dump trucks.

5. The use of liquefied natural gas (LNG) as a motor fuel for BelAZ 75131 mining dump trucks does not affect the formation of lead in waste oil of CUMMINS KTA 50 diesel internal combustion engines.

\section{References}

1. A.V. Kudrevatykh, Bulletin of the Kuzbass State Technical University, 1 (2020)

2. D.V. Stenin, N.A. Stenina, A.A. Bakanov, Coal in the 21 st Century: Mining, Processing and Safety (2016)

3. A.V. Kudrevatykh, Mining Equipment and Electromechanics, 5 (2020)

4. A.V. Kudrevatykh, E3S Web Conf., 105, 03021 (2019)

5. Q. Sunqing, D. Junxiu, Ch. Guoxu, Lubricating Science, vol. 11, 3 (1999)

6. A.V. Kudrevatykh, A.S. Ashcheulov, A.S. Ashcheulova, IOP Conf. Series: Materials Science and Engineering, 537, 032033 (2019).

7. I.V. Kuznetsov, I.A. Panachev, G.M. Dubov, S.A. Nohrin, Handbook. An Engineering journal, 4, 265 (2019)

8. I.V. Kuznetsov, I.A. Panachev, G.M. Dubov, S.A. Nohrin, E3S Web Conf., 174, 03010 (2020)

9. G.M. Dubov, D.S. Trukhmanov, I.V. Kuznetsov, S.A. Nokhrin, A.N. Sergel, E3S Web Conf., 105, 03019 (2019)

10. D.M. Dubinkin, Mining Equipment and Electromechanics, 6, 146, (2019).

11. D.M. Dubinkin, V.Yu. Sadovets, G.O. Kotiev, A.V. Kartashov, Journal of mining and geotechnical engineering, 4, 7, (2019)

12. S.G. Kostyuk, B.A. Fedosenkov, I.V. Chicherin, D.M. Dubinkin. Sustainable development of mountain territories. 4, 600 (2020).

13. D.M. Dubinkin Mining Equipment and Electromechanics. 4, 59 (2020)

14. G.M. Dubov, D.S. Trukhmanov, S.A. Nokhrin, IOP Conf. Series: Earth and Environ. Sci., 459, 042059 (2020)

15. G.M. Dubov, D.S. Trukhmanov, S.A. Nokhrin, A.N. Sergel, MATEC Web Conf., 297, 03002 (2019)

16. S.S. Azikhanov, A.R. Bogomolov, G.M. Dubov, S.A. Nokhrin, MATEC Web Conf., 297, 03001 (2019)

17. G.M. Dubov, D.S. Trukhmanov, I.V. Kuznetsov, S.A. Nokhrin, A.N. Sergel, E3S Web Conf., 105, 03018 (2019)

18. S.A. Nohrin, G.M. Dubov, D.S. Trukhmanov, Patent 2701133 (The Russian Federation, 2019)

19. G.M. Dubov, D.S. Trukhmanov, S.A. Nokhrin, A.N. Sergel, E3S Web Conf., 174, 03016 (2020)

20. M.L. Khazin, PJPME, vol. 19, 1, 56 (2019) 